\title{
OSSEOUS GROWTH AND SACRALISATION IN SACRUM - A CASE REPORT
}

\author{
Kishore Chandra Thakur1, S. L. Jethani
}

${ }^{1}$ Assistant Professor, Department of Anatomy, Himalayan Institute of Medical Sciences, SRHU, Dehradun.

2 Professor and HOD, Department of Anatomy, Himalayan Institute of Medical Sciences, SRHU, Dehradun.

\begin{abstract}
BACKGROUND

A very common congenital anomaly called lumbosacral transitional vertebrae is seen in sacrum, which includes sacralisation and lumbralisation. Sacralisation is characterised by presence of partial or complete fusion of fifth lumbar vertebra with first sacral vertebra. During regular teaching of undergraduates, one sacrum was noticed with significant variation having large osseous growth on pelvic surface along with sacralisation of fifth lumbar vertebra. An osseous growth was extending on pelvic surface from right side of fourth lumbar vertebral body to body of sacralised fifth lumbar vertebra. Sacralisation of fifth lumbar vertebra along with fixation of fourth vertebra because of osseous growth can be the cause of early age back pain in an individual due to shift of seat of spinal movement to third lumbar vertebra above. Misexpression of HOX genes during intrauterine life is considered as cause of it. Such kind of sacral variation altogether can lead to delayed and difficult delivery of baby in female due to change in pelvic dimension and its biomechanics. Neurovascular and visceral compression manifestation can be a chief complaint of an individual with such variation in sacrum. Neurosurgeons and anaesthetist need to be alert regarding such possible variation to prevent faulty spinal surgery and spinal anaesthesia respectively.
\end{abstract}

\section{KEYWORDS}

Lumbosacral Transition Vertebra, Sacralisation, Osseous Growth.

HOW TO CITE THIS ARTICLE: Thakur KC, Jethani SL. Osseous growth and sacralisation in sacrum - a case report. J. Evolution Med. Dent. Sci. 2016;5(93):6899-6901, DOI: 10.14260/Jemds/2016/1560

\begin{tabular}{lc}
\hline BACKGROUND & $\begin{array}{c}\text { Sacralisation of fifth lumbar vertebra in addition to } \\
\text { Sacrum has drawn attention of various medical fields due to its }\end{array}$
\end{tabular}
anatomical position and variability. Neuroradiologists consider sacrum as part of spinal axis; trauma radiologist as part of skeletal system and abdominal radiologist consider it as a part of pelvis.[1] Sacrum bone is normally formed by fusion of five sacral vertebrae and articulates with the fifth lumbar vertebra at its base and with coccyx at its apex. Anterior surface of sacrum include the ala, sacral promontory, five vertebral bodies and four pairs of pelvic sacral foramina. Concavity of anterior part of sacrum increases the depth of pelvic cavity. It receives and bears transmitted body weight of trunk on its large first sacral body and ala, which is further transmitted to sacroiliac joint and then from acetabula to femur in erect posture. Developmental anomalies of sacrum are widely reported and studied in past. Sacralisation of fifth lumbar vertebra is common congenital anomaly seen as one of the variant of lumbosacral transitional vertebrae. Partial or complete fusion of fifth lumbar vertebrae with first sacral vertebra is called sacralisation. Clinical significance of age related vertebral degenerative disease like spondylosis deformans and the high incidence of easily detected bony osteophytes have shown correlation to musculoskeletal or neurologic disease. Any abnormal osseous growth on pelvic surface of sacrum can lead to effective decrease in pelvic dimensions and compression of related structures with their clinical manifestations.

Financial or Other, Competing Interest: None.

Submission 18-10-2016, Peer Review 12-11-2016,

Acceptance 17-11-2016, Published 21-11-2016.

Corresponding Author:

Dr. Kishore Chandra Thakur,

H. No. 33, Ground Floor, Lane-2,

Madhu Vihar, Haripur, Kanwali,

GMS Road, Dehradun-248001,

Uttarakhand.

E-mail: thakurdon@yahoo.com,bestthakur@hotmail.com

DOI: $10.14260 /$ jemds $/ 2016 / 1560$

\section{CASE REPORT}

During routine teaching of osteology to undergraduates, a dry human sacrum bone of unknown age and sex was noticed having abnormal osseous growth on its ventral surface along with sacralisation of fifth lumbar vertebrae. This sacrum was formed from 6 fused vertebrae. There was five pair of sacral foramina instead of four pair of foramina seen in normal sacrum on ventral and dorsal surface. Body of fifth lumbar vertebra was completely fused with body of first sacral vertebra and proper ala was formed by fused transverse process of fifth lumbar vertebra. No partial separation was present between any part of fifth lumbar vertebra and first sacral vertebra on pelvic and dorsal surface denoting complete sacralisation of fifth lumbar vertebra (Figure 1).

Large globular abnormal osseous growth was present on right side of pelvic surface of fourth lumbar vertebra and sacralised fifth lumbar vertebra (Figure 2). Superiorly, growth was extending horizontally from mid of upper border of vertebral body to base of right transverse process of fourth lumbar vertebra. Inferiorly growth was extending horizontally from mid of sacralised lumbar vertebra to commencement of right side of ala osseous growth in its mid portion was projecting anteriorly and bridging the right side of body of fourth lumbar vertebra to right side of body of sacralised fifth lumbar vertebra. Noted side-to-side widths of osseous growth by Vernier Caliper in mm are: upper (fourth lumbar) $=42 \mathrm{~mm}$, mid-portion (between fourth lumbar and sacralised fifth lumbar) $=36 \mathrm{~mm}$, lower (sacralised fifth lumbar) $=30 \mathrm{~mm}$. Anteroposterior extension of mass in mid portion was $17 \mathrm{~mm}$. Superior surface of fourth lumbar vertebra was sloping down towards right side giving slightly compressed look to its body on its right side. Superior part of osseous growth present in relation to fourth lumbar vertebra was rough with numerous vascular foramina, whereas inferior part in relation to sacralised fifth lumbar vertebra was comparatively smooth 
with less number of vascular foramina. There was no extension of osseous growth into vertebral canal and over nearby sacral foramina. Right intervertebral foramen between fourth and sacralised fifth lumbar vertebra was obstructed to some extent. Intervertebral disc space between body of fourth lumbar and sacralised fifth lumbar was reduced on right side in comparison to left side.

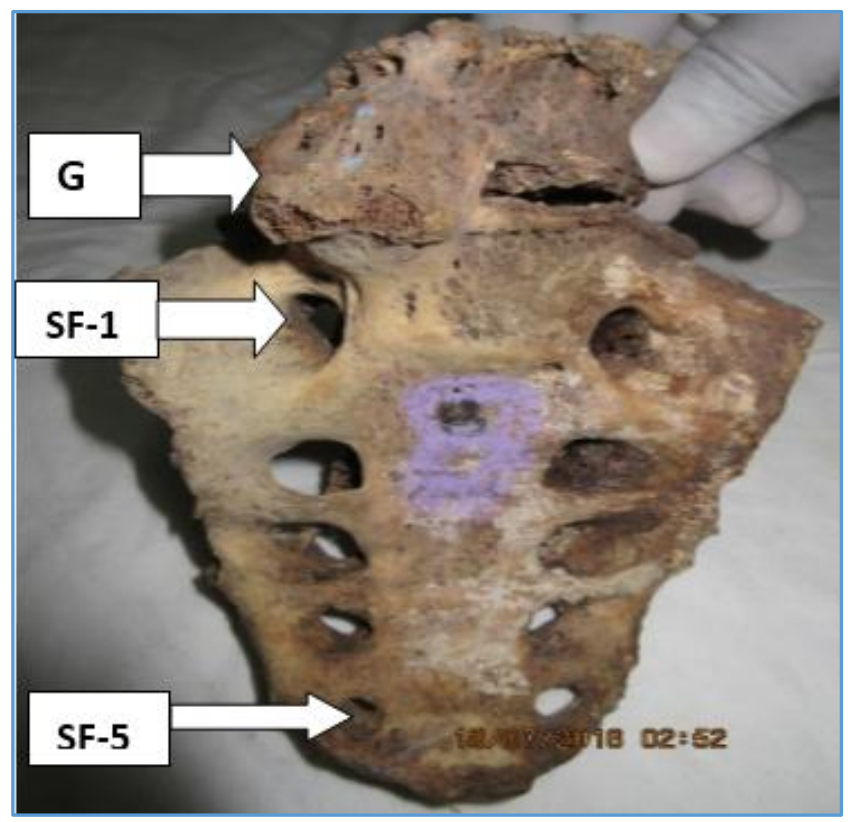

Figure 1

Sacrum: Osseous Growth with Sacralised Fifth Lumbar Vertebra

(G: Osseous Growth SF - 1: First Sacral Foramina SF - 5: Fifth Sacral Foramina)

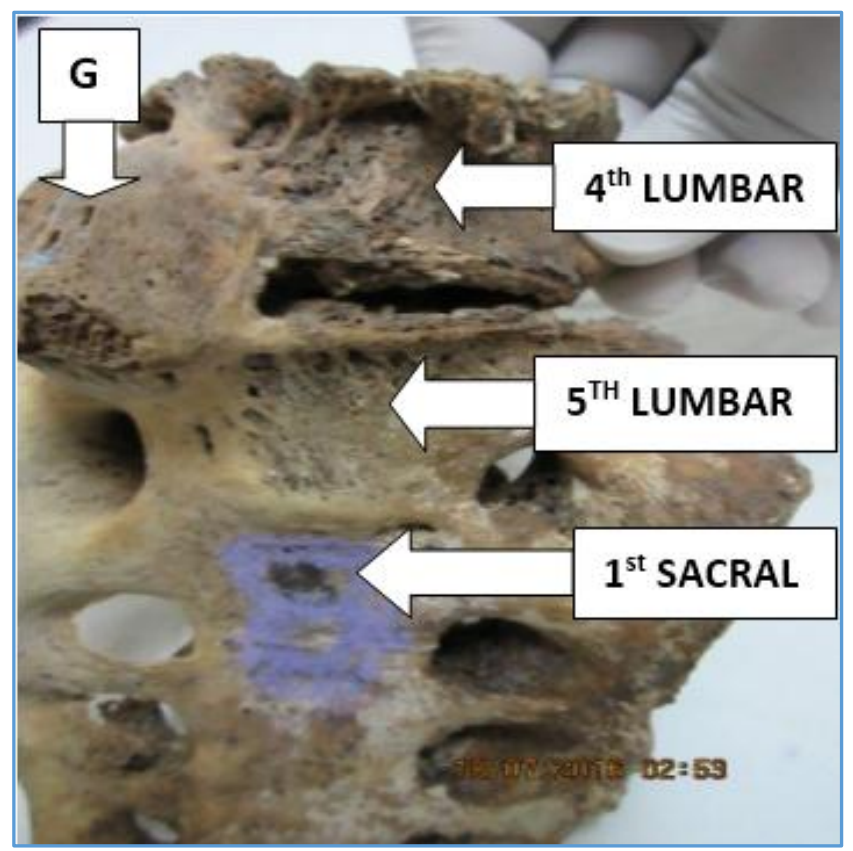

Figure 2

\section{DISCUSSION}

Each vertebra embryologically formed from combination of caudal half of one sclerotome and the cranial half of succeeding sclerotome regulated by HOX genes. Carapuco et al (2003) in his study explained the role of HOX 11 expression by inducing sacralisation in vertebra of transgenic mice.[2] Wellik et al (2005) later supported the role of HOX 11 expression by showing lack of sacral vertebra formation in absence of HOX 11.[3] Defect in expression of homeobox and paired-box genes (Pax 1 and Pax 9), which control cell proliferation during early sclerotome development results in boundary shifts at the transitional areas of the vertebral column leading to lumbarisation and sacralisation. Lumbarisation caused due to caudal shift, whereas sacralisation refers to a cranial shift.

Kubavat Dharati et al observed $11.1 \%$ sacralisation of fifth lumbar vertebrae in Gujarati population. ${ }^{[4]}$ Peter et al reported $6.2 \%$ sacralisation. ${ }^{[5]}$ Deepa et al noted sacralisation in $10.25 \%$ cases in south Indian population. ${ }^{[6]}$ But none of them reported any osseous growth as seen in present case.

Sacralisation of the fifth lumbar segment alters the centre of gravity of base of the spine along with joint mobility. Due to sacralisation of fifth lumbar, the seat of spinal movement changes from fifth lumbar to fourth lumbar vertebra above. In present case, due to fixity of fourth lumbar with sacralised fifth lumbar because of osseous growth, seat of spinal movement further shifted up to third lumbar vertebra. Normally, fifth lumbar vertebra is firmly anchored to inner pelvic bones securing spine to the sacral table by various ligaments. In absence of fifth lumbar vertebra as a separate bone and fixity of fourth lumbar, as in present case can make an individual prone to early age back pain along with postural change.

Large osseous growth on sacral promontory of human is rarely reported. Puja et al (2010) reported osseous growth on left side of sacral promontory without any lumbosacral transitional vertebral anomaly like sacralisation or lumbarisation. [7]

In present case report, osseous growth noticed, but on right side of sacralised fifth lumbar and body of fourth lumbar vertebra. Such growth may result from failure or disturbance in sequence of formation of vertebral bodies during intrauterine life. Some researchers suggest the presence of ventral and dorsal primary ossification center separately instead of one for centrum development of vertebra. Considering this point of view, overgrowth of ventral primary ossification center may be the cause of such osseous growth. Some researchers suggest that cartilage cells of epiphyseal plate are arranged in form of vertical columns and their abnormal secondary ossification can lead to osseous growth at vertebra.[8] This growth can be the overgrowth of osteophytes, which is rare in humans. Vertebral osteophytes of variable size extending up to the midpoint of the ventral aspect of vertebral body are common in dogs, because of appearance of separate centers of ossification in the ventral portion of the annulus. Spurs are periarticular, as they arise from the circumference of the end-plate.

Hoerlein (1956) described vertebral osteophytes affecting the vertebral column of the dog and its clinical aspects.[9] Hypervitaminosis $\mathrm{A}$ in the cat can cause bridging type of vertebral osteophytes. In multiple osteochondromatosis of dog solitary form of osteophyte may be present within the spinal canal which ceases in growth after a limit, whereas in cat bony masses occur and grow to massive size later in life.[9]

Because of sacralisation and osseous growth, anteroposterior diameter of pelvis and pelvic mobility both are decreased. This can lead to delay in engagement of head of foetus, difficult descent and internal rotation of head of baby resulting into delayed or obstructed labour in females. 
Sacralisation can cause faulty spinal anaesthesia and spinal surgery due to wrong spine level counting.

Such a large pendulous growth on right side of sacralised lumbar vertebra can cause compression of related neurovascular structures like right common iliac vein, inferior vena cava, right common iliac artery, right sympathetic chain, right lumbosacral trunk, ureter and rectum leading to respective pressure symptoms like oedema or necrosis of lower limb, constipation, bladder and bowel dysfunction, etc.

\section{CONCLUSION}

Large osseous growth on anterior surface of lumbosacral region along with sacralisation of fifth lumbar vertebra rarely reported earlier, instead separately they are reported. Such variant may be alert for medical fraternity treating patient of neurovascular manifestations of pelvic region and below it.

\section{REFERENCES}

1. Diel J, Ortiz 0, Losada RA, et al. The sacrum: pathologic spectrum, multimodality imaging \& subspecialty approach. Radiographics 2001;21(1):83-104.
2. Carapuco M, Nóvoa A, Bobola N, et al. Hox genes specify vertebral types in the presomitic mesoderm. Genes Dev 2005;19(18):2116-21.

3. Wellik DM, Capecchi MR. Hox10 and Hox11 genes are required to globally pattern the mammalian skeleton. Science 2003;301(5631):363-7.

4. Dharati K, Nagar. A study of sacralisation of fifth lumbar vertebra in Gujarat. N J Medical Research 2012;2(2):21113.

5. Peters H, Wilm B, Sakai N, et al. Pax1 \& Pax 9 synergistically regulate vertebral column. Development 1999;126(23): 5399-408.

6. Deepa TK, John MK. A study of lumbarisation of first sacral vertebra among the South Indians. Int J Med Res Health Sci 2014;3(1):1-4.

7. Chauhan $P$, Kalra S. A rare osseous growth on sacrum. Int J Anat Var 2010;3:218-19.

8. Morgan JP. Spondylosis derformans in the dog. A morphologic study with some clinical and experimental observations. Acta Orthop Scand 1967:38(96):1-88.

9. Hoerlein BF. Clinical spinal conditions in the dog. Vet Med 1956;51:575. 